\title{
VALIDITAS E-MODUL PEMANASAN GLOBAL BERBASIS CREATIVE PROBLEM SOLVING UNTUK SISWA SMP KELAS VII
}

\author{
Leni Eka Putri ${ }^{1}$, I Ketut Mahardika ${ }^{2}$, Iwan Wicaksono ${ }^{3}$ \\ ${ }^{123}$ Fakultas Keguruan dan Ilmu Pendidikan, Universitas Jember \\ e-mail: putrilenieka11@gmail.com
}

\begin{abstract}
ABSTRAK
Penelitian ini bertujuan untuk mengembangkan e-modul pemanasan global berbasis creative problem solving yang valid untuk digunakan siswa SMP kelas VII. Model pengembangan yang digunakan dalam penelitian ini adalah model pengembangan ADDIE yang terdiri dari 5 tahapan yaitu tahap analisis (analysis), tahap perancangan (design), tahap pengembangan (development), tahap implementasi (implementation), dan tahap evaluasi (evaluation). Pengumpulan data pada penelitian ini dilakukan melalui proses validasi e-modul oleh validator ahli. Data yang diperoleh dilakukan analisis deskriptif. Penelitian ini menggunakan satu kelas yaitu kelas VII B dengan jumlah siswa sebanyak 32 siswa. Hasil penelitian menunjukan bahwa e-modul pemanasan global berbasis creative problem solving memenuhi kriteria kevalidan yaitu valid konstruk dan valid isi yang tertuang dalam 8 aspek penilaian meliputi aspek relevansi materi, aspek pengorganisasian materi, aspek evaluasi, aspek bahasa, aspek efek bagi strategi pembelajaran, aspek rekayasa perangkat lunak, aspek tampilan visual, dan aspek pengorganisasian e-modul. E-modul pemanasan global berbasis creative problem solving dinyatakan valid dengan memperoleh rata-rata persentase skor penilaian dari 3 validator ahli sebesar $95,71 \%$ yang termasuk dalam kategori sangat valid. Hal ini menunjukkan bahwa e-modul pemanasan global berbasis creative problem solving yang dikembangkan valid untuk digunakan sebagai salah satu media alternatif dalam proses pembelajaran
\end{abstract}

Kata Kunci: e-modul, pemanasan global, creative problem solving

\section{ABSTRACT}

This study aims to develop an e-module on global warming based on creative problem solving that is valid for use seventh grade junior high school students. The development model used in this study id the ADDIE development model which consists of 5 stages, namely the analysis stage, the design stage, the development stage, the implementation stage, and the evaluation stage. Data collection in this study was carried out through an e-module validation process by expert validators. The data obtained were analyzed descriptively. This study used one class, namely class VII B with a total of 32 students. The results showed that the e-module on global warming based on creative problem solving met the validity criteria, namely valid constructs and valid content contained in 8 aspects of the assessment including aspects of material relevance, aspects of material organization, aspects of evaluation, language aspects, aspects of effects for learning strategies, aspects of software engineering, 
visual display aspects, and e-module organizing aspects. The e-module on global warming based on creative problem solving is declared valid by obtaining an average percentage score of 95,71\% from 3 expert validators which is included in the very valid category. This shows that the e-module on global warming based on creative problem solving that was developed is valid to be used as an alternative media in the learning process.

\section{Keywords: e-module, global warming, creative problem solving}

\section{PENDAHULUAN}

Memasuki abad ke-21, bidang sains dan teknologi telah mengalami perubahan yang pesat dalam meningkatkan kualitas hidup manusia. Seringkali perubahan tersebut disertai dengan munculnya permasalahan-permasalahan baru baik dari segi moral, etika maupun isuisu global yang dapat mengancam kelangsungan hidup manusia. Salah satu isu global yang saat ini dapat dirasakan dengan jelas dampaknya adalah pemanasan global, mulai dari peningkatan suhu hingga perubahan iklim yang ditandai dengan cuaca yang tidak menentu. Tetapi pemahaman mengenai konsep dasar materi pemanasan global sangat diperlukan dan ditekankan kepada siswa sejak dini, sehingga siswa dapat memiliki kesadaran untuk melakukan pencegahan dan menentukan upaya penyelesaian yang tepat guna mengatasi pemanasan global ini. Pada kenyataannya, sebagian besar siswa masih mengalami kesulitan untuk dapat memahami konsep materi pemanasan global secara mandiri. Terutama di era pembelajaran daring ini yang memungkinkan belajar mandiri lebih efektif dikarenakan kemampuan setiap siswa dalam memahami materi berbeda-beda. Salah satu faktor yang menyebabkan hal tersebut adalah kurangnya inovasi media pembelajaran yang dapat memudahkan siswa memahami materi pemanasan global secara mandiri (Sibarani et al., 2019).

Konsep materi pemanasan global menuntut siswa untuk dapat menganalisis gejala dan dampaknya terhadap kehidupan, sehingga siswa dapat mengajukan gagasan sebagai solusi untuk mengatasi permasalahan tersebut (Kemendikbud, 2016). Siswa masih kesulitan mencapai hal tersebut dikarenakan konsep gejala pemanasan global yang bersifat abstrak (Setianita et al., 2019). Hal ini sejalan dengan penelitian yang telah dilakukan oleh Rustia et al. (2015) menyatakan bahwa sebanyak $81,25 \%$ siswa menganggap sulit materi pemanasan global dikarenakan kesulitan dalam menjawab soal-soal berupa essay atau permasalahan. Penelitian lain juga dilakukan oleh Yazdanparast et al. (2013) menunjukkan bahwa hanya 5,1\% dari 1035 siswa yang dapat menjelaskan efek rumah kaca dengan benar, teliti dan lengkap. Penelitian yang dilakukan oleh Freije et al. (2017) juga menemukan bahwa hanya $(55 \pm 10,18) \%$ dari 143 sampel siswa yang memahami materi pemanasan global.

Permasalahan tersebut juga ditemukan di SMP Negeri 12 Gresik. Berdasarkan wawancara dengan guru IPA SMP Negeri 12 Gresik (1/03/2021) dihasilkan informasi bahwa siswa masih kesulitan dalam memahami materi pemanasan global, dikarenakan materi pemanasan global memiliki karakteristik berupa bacaan dan hafalan. Beberapa siswa juga menganggap bahwa ada beberapa konsep materi pemanasan global yang dianggap abstrak yaitu salah satunya mengenai proses efek rumah kaca. Siswa juga mengalami kesulitan memahami materi yang berasal dari LKPD dan buku paket, karena kemungkinan media pembelajaran yang digunakan kurang menarik sehingga mempengaruhi motivasi belajar siswa. Motivasi sangatlah penting menurut Prasetyo (2015), motivasi merupakan daya 
penggerak agar siswa berusaha belajar dan keberlangsungan kegiatan belajar siswa lebih terjamin yang mendorong tujuan pembelajaran dapat tercapai. Guru sebenarnya telah menggunakan metode yang bervariatif, akan tetapi masalah yang ada adalah penggunaaan media yang masih bersifat sederhana seperti buku paket dan LKPD sebagai media utama dalam proses pembelajaran.

Solusi yang diberikan peneliti adalah bahwa guru memerlukan inovasi media pembelajaran berbasis mobile learning yang mendukung pembelajaran daring yang mudah diakses dan memungkinkan siswa dapat belajar secara mandiri serta mampu memadukan konsep-konsep pemanasan global secara tepat, sehingga pemilihan media pembelajaran sangatlah penting dan tidak boleh diabaikan. Media pembelajaran yang digunakan juga diharapkan mampu menimbulkan semangat belajar bagi siswa untuk mempelajari lebih dalam topik yang dibahas dalam media tersebut. Menurut Pramita dan Agustini (2016), media pembelajaran dapat menumbuhkan motivasi belajar siswa dan meningkatkan pemahaman konsep siswa.

Salah satu media pembelajaran yang memungkinkan siswa untuk belajar mandiri adalah e-modul. E-modul dapat didukung dengan suatu model pembelajaran agar mempermudah siswa dalam proses pembelajaran, maka dipilihlah model pembelajaran creative problem solving (CPS). Model ini menekankan pada pemecahan masalah secara kreatif, sehingga sangat cocok dengan materi pemanasan global yang menuntut siswa untuk dapat menganalisis gejala pemanasan global dan dampaknya terhadap kehidupan. Menurut penelitian yang telah dilakukan oleh swestyani et al. (2014) bahwa modul IPA berbasis Creative Problem Solving (CPS) pada materi pemanasan global efektif untuk meningkatkan kemampuan berpikir kreatif siswa dengan perolehan $N$-gain score sebesar 0,368 yang menunjukan kategori tinggi. Pemecahan masalah secara kreatif melibatkan keterampilan pemecahan masalah dan keterampilan berpikir kreatif. Dengan kemampuan memecahkan masalah secara kreatif diharapkan dapat mendorong motivasi dan hasil belajar siswa menjadi lebih baik. Sehingga e-modul pemanasan global berbasis Creative Problem Solving dikembangkan dengan strategi pembelajaran berupa pemberian stimulus siswa yang mengarahkan siswa menggali pemahaman materi tersebut untuk menemukan permasalahan dan pemecahan atau solusinya yang paling tepat secara kreatif. Sintaks model pembelajaran creative problem solving dapat diterapkan pada e-modul untuk memudahkan dalam langkahlangkah pembelajaran. Oleh karena itu, perlu adanya suatu pengembangan yang dapat menghasilkan produk berupa e-modul pemanasan global berbasis creative problem solving.

E-modul pemanasan global berbasis creative problem solving harus memiliki kategori valid agar layak digunakan dalam pembelajaran. Menurut Nieveen, validitas berarti shahih atau sesuai dengan ketentuan yang seharusnya (Nieveen, 2013). Validitas berasal dari bahasa inggris yaitu validity artinya kebenaran atau keabsahan (Rochmad, 2012). Menurut Yusuf (2005) validitas adalah uji untuk menilai suatu produk yang dihasilkan dari penelitian pengembangan. Terdapat empat aspek komponen validitas yaitu kelayakan penyajian, kelayakan kebahasaan, kelayakan kegrafikaan, dan kelayakan isi (Depdiknas, 2008). Validitas menurut Arikunto (2008) terbagi menjadi dua garis besar yaitu validitas logis dan validitas empiris. Validitas logis ditinjau dari persyaratan valid berdasarkan hasil penalaran. Validitas empiris ditinjau melalui pengujian atau diuji dari pengalaman. Syarat media pembelajaran layak menurut pendapat Nieveen adalah memenuhi validitas konstruk dan 
validitas isi. Validitas konstruk adalah konsistensi seluruh komponen media pembelajaran terkait satu satu sama lain. Validitas isi adalah komponen media pembelajaran didasarkan pada pengetahuan mutakhir dan memenuhi suatu kebutuhan (Nieveen, 2013).

Penelitian ini mengadaptasi kevalidan menurut Nieveen yaitu valid isi dan valid konstruk yang tertuang dalam delapan aspek penilaian yaitu meliputi aspek relevansi materi, aspek pengorganisasian materi, aspek evaluasi/latihan soal, aspek bahasa, aspek efek bagi strategi pembelajaran, aspek rekayasa perangkat lunak, aspek tampilan visual, dan aspek pengorganisasian e-modul. Validasi e-modul bertujuan untuk menghasilkan e-modul yang valid melalui uji validitas (Akbar, 2016). Validitas e-modul pemanasan global berbasis creative problem solving merupakan hal yang sangat penting untuk melihat keshahian atau ketepatan materi yang disampaikan. Tujuan penelitian ini adalah untuk mengetahui tingkat validitas e-modul pemanasan global berbasis creative problem solving. Sehingga dapat layak digunakan dalam proses pembelajaran.

\section{METODE}

Penelitian ini menggunakan metode penelitian R \& D (Research and Development). Metode penelitian ini digunakan, apabila bertujuan untuk menghasilkan produk dan menguji kualitas produk tersebut. Produk tersebut adalah e-modul pemanasan global berbasis creative problem solving untuk siswa SMP kelas VII. Model pengembangan yang digunakan adalah model pengembangan ADDIE (Analysis, Design, Development, Implementation, dan Evaluation). Model ini dipilih karena bersifat sederhana dan sistematis sehingga mudah untuk dipahami dan dipelajari.

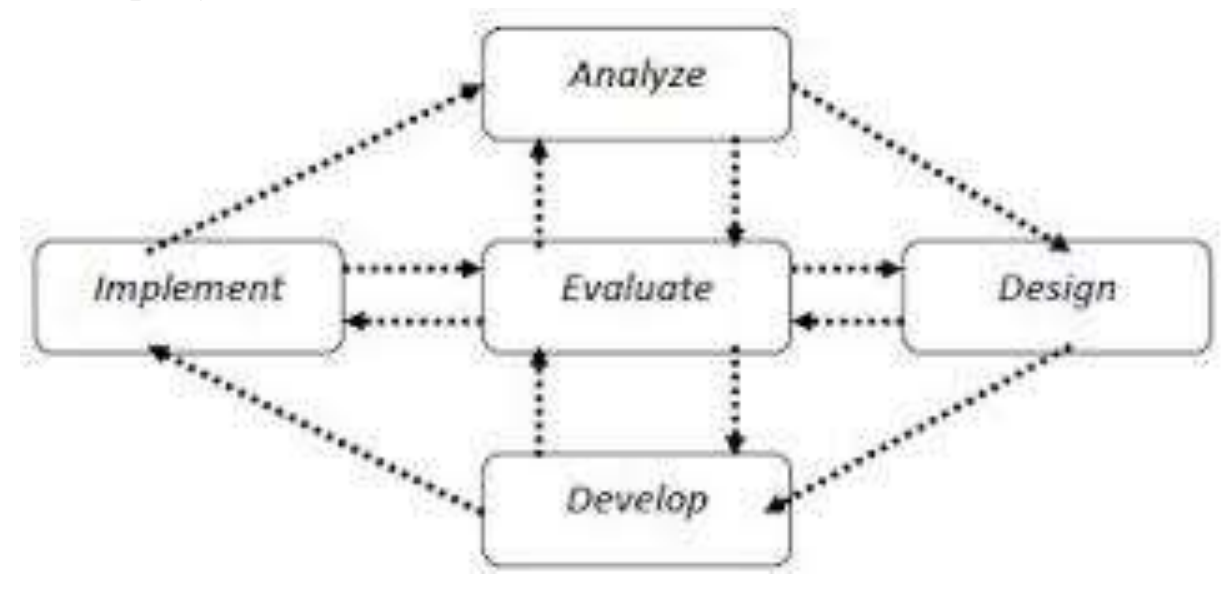

\section{Gambar 1. Tahapan Model Pengembangan ADDIE (Tegeh et al., 2014)}

Penelitian ini dilakukan di SMP Negeri 12 Gresik. Subjek penelitian untuk uji coba kelompok kecil adalah siswa kelas VII B sejumlah 6 siswa yang direkomendasikan guru IPA yang memiliki kemampuan kognitif tinggi, sedang dan rendah. Uji coba lapangan dilakukan oleh 32 siswa kelas VII B. Instrumen penelitian yang digunakan untuk mengukur kevalidan yaitu lembar validasi, lembar uji coba kelompok kecil dan lembar uji coba kelompok besar. Teknik analisis statistik deskriptif digunakan untuk menganalisis data hasil uji coba pengembangan e-modul ini. Pada penelitian ini, validator ahli yang memvalidasi e-modul pemanasan global berbasis creative problem solving yang dikembangkan yaitu 1 (satu) dari 
dosen Universitas Jember dan 2 (dua) dari guru SMP Negeri 12 Gresik. Data yang diperoleh kemudian dilakukan analisis kevalidan menggunakan rumus validitas menurut Akbar (2016).

\section{HASIL DAN PEMBAHASAN}

Hasil penelitian pengembangan e-modul pemanasan global berbasis creative problem solving adalah hasil validitas e-modul. Berikut gambaran e-modul pemanasan global berbasis creative problem solving yang dikembangkan yang terdiri dari beberapa menu utama yaitu home, petunjuk, pendahuluan, KI dan KD, peta konsep, kegiatan pembelajaran, rangkuman, glosarium, daftar pustaka, dan profil. Pada menu kegiatan pembelajaran terdapat 3 materi yang disajikan yaitu materi efek rumah kaca, materi pengertian dan penyebab pemanasan global, dan materi dampak dan upaya penanggulangan pemanasan globalPada setiap menu materi tersebut terdiri dari lima submenu yaitu kegiatan belajar, uraian materi, tahukah kamu, latihan pengayaan, dan tes formatif.

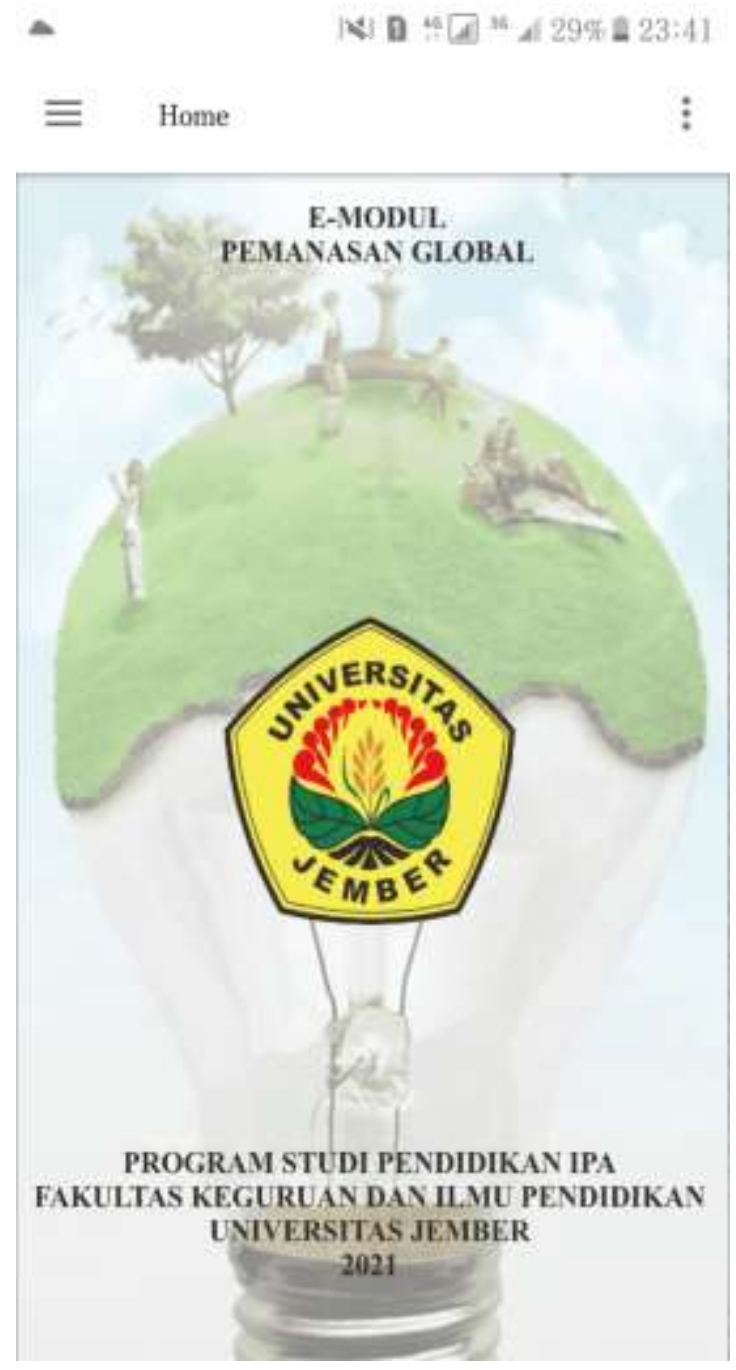

Gambar 2. Home Screen (Beranda) 


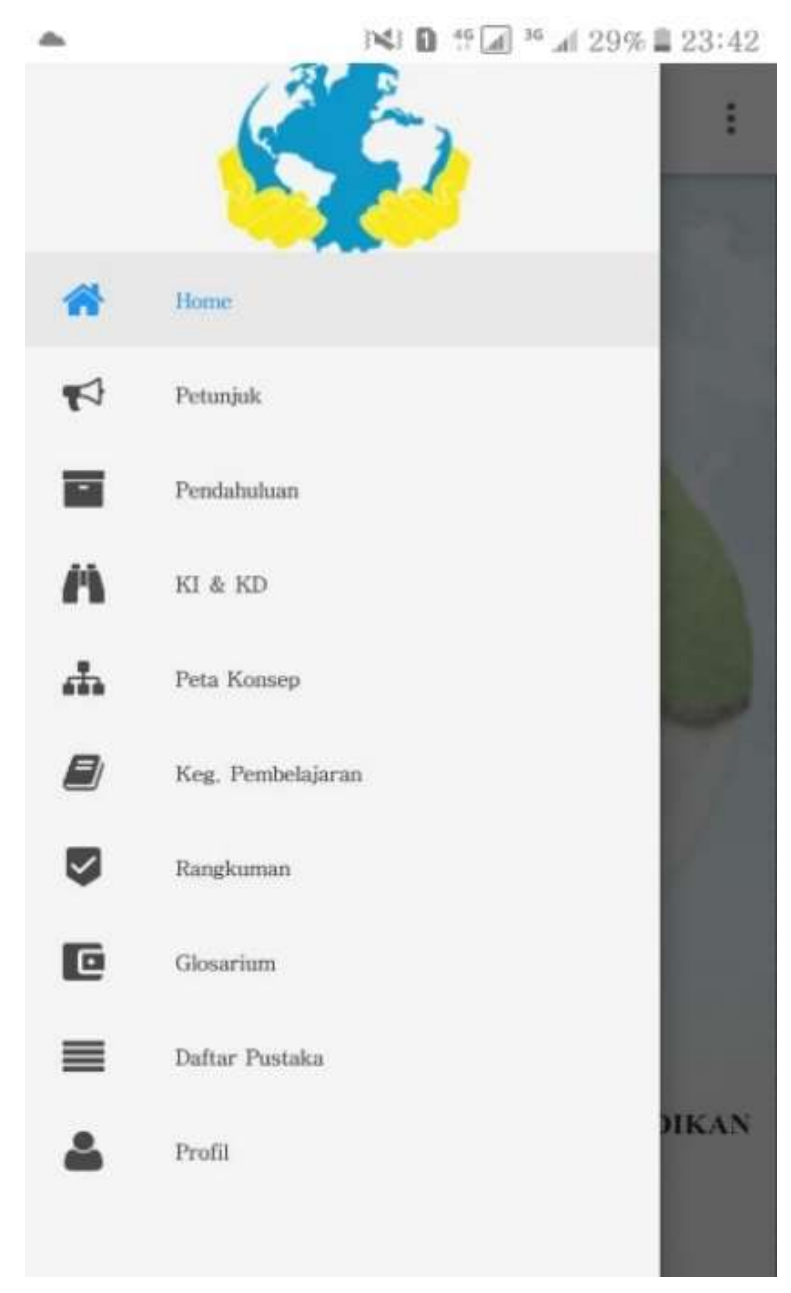

Gambar 3. Screen Menu Utama

E-modul pemanasan global berbasis creative problem solving dilakukan validasi konstruk dan validasi isi oleh tiga validator ahli dengan lembar validasi memiliki 33 indikator yang dikelompokkan menjadi 8 aspek penilaian yaitu meliputi aspek relevansi materi, aspek pengorganisasian materi, aspek evaluasi/latihan soal, aspek bahasa, aspek efek bagi strategi pembelajaran, aspek rekayasa perangkat lunak, aspek tampilan visual, dan aspek pengorganisasian e-modul.

Secara keseluruhan rata-rata hasil penilaian dari ketiga validator ahli diperoleh persentase sebesar $95,71 \%$ dengan kategori sangat valid. Berdasarkan hasil validasi oleh validator ahli dan kriteria validitas menurut Akbar (2016: 81) dapat disimpulkan bahwa emodul pemanasan global berbasis creative problem solving berada dalam kategori $80,00 \%$ $100,00 \%$ yaitu sangat valid atau dapat digunakan dalam pembelajaran.

Uji coba kelompok kecil dilakukan pada tanggal 5 April 2021 yang dilakukan oleh 6 orang siswa kelas VII SMP Negeri 12 Gresik. Uji coba ini bertujuan untuk mengetahui pendapat dan evaluasi siswa apakah e-modul pemanasan global membutuhkan perbaikan atau tidak. Uji coba ini dilakukan dengan memberikan angket kepada siswa setelah melaksanakan pembelajaran dengan menggunakan e-modul pemanasan global berbasis creative problem solving. Hasil penilaian pada uji coba kelompok kecil diperoleh rata-rata sebesar 93,59\% yang menunjukan bahwa e-modul pemanasan global berbasis creative problem solving termasuk dalam kategori sangat valid untuk digunakan dalam pembelajaran. Hasil uji coba 
kelompok kecil ini tidak terdapat masukan atau saran untuk melakukan perbaikan pada emodul. Berikut adalah rekapitulasi hasil penelitian lapang dapat dilihat pada Tabel 1.

Tabel 1. Hasil Uji Coba Kelompok Kecil

\begin{tabular}{|c|c|c|c|}
\hline No & Aspek Penilaian & Validitas \% & Kategori \\
\hline 1 & Media E-Modul & $95,83 \%$ & Sangat Valid \\
\hline 2 & Materi & $91,67 \%$ & Sangat Valid \\
\hline 3 & Manfaat & $95,83 \%$ & Sangat Valid \\
\hline \multicolumn{2}{|c}{ Total } & $93,59 \%$ & Sangat Valid \\
\hline
\end{tabular}

Uji coba lapangan dilakukan pada tanggal 12 April 2021 yang dilakukan oleh 32 siswa kelas VII B SMP Negeri 12 Gresik. Penyebaran e-modul dilakukan melalui WhatsApp, google drive dan email. Siswa mendownload dan menginstall e-modul sebelum digunakan. Setelah pembelajaran dengan menggunakan e-modul pemanasan global berbasis creative problem solving, siswa diberikan angket untuk menilai e-modul apakah memerlukan revisi atau tidak berdasarkan aspek media e-modul, aspek materi dan aspek manfaat. Hasil penilaian pada uji coba lapangan diperoleh rata-rata sebesar 92,73\% yang menunjukan bahwa e-modul pemanasan global berbasis creative problem solving termasuk dalam kategori sangat valid untuk digunakan dalam pembelajaran. Berikut adalah rekapitulasi hasil penelitian lapang dapat dilihat pada Tabel 2.

Tabel 2. Hasil Uji Coba Lapangan

\begin{tabular}{|c|l|c|c|}
\hline No & Aspek Penilaian & Validitas $\%$ & Kategori \\
\hline 1 & Media E-Modul & $92,38 \%$ & Sangat Valid \\
\hline 2 & Materi & $92,08 \%$ & Sangat Valid \\
\hline 3 & Manfaat & $95,70 \%$ & Sangat Valid \\
\hline \multicolumn{2}{|c|}{ Total } & $92,73 \%$ & Sangat Valid \\
\hline
\end{tabular}

E-modul pemanasan global berbasis creative problem solving dinyatakan valid. Karena telah memenuhi kriteria kevalidan yaitu valid konstruk dan valid isi yang tertuang pada beberapa aspek penilaian validitas yaitu aspek relevansi materi, aspek pengorganisasian materi, aspek evaluasi/latihan soal, aspek bahasa, aspek efek bagi strategi pembelajaran, aspek rekayasa perangkat lunak, aspek pengorganisasian e-modul dan aspek tampilan visual dimana e-modul mendapatkan skor dengan kategori sangat valid berdasarkan hasil penilaian validator ahli. E-modul dinyatakan valid karena berdasarkan penilaian validator ahli diketahui bahwa e-modul memenuhi penilaian aspek relevansi materi dengan kategori sangat valid. Hal ini menunjukkan bahwa materi yang disampaikan dalam e-modul sesuai dengan $\mathrm{KI}, \mathrm{KD}$, indikator dan tujuan pembelajaran serta disajikan sesuai dengan konsep dan definisi yang berlaku di bidang IPA. Untuk aspek pengorganisasian materi e-modul mendapatkan kategori sangat valid berdasarkan penilaian validator ahli. Hal ini menunjukkan bahwa materi yang disampaikan dalam e-modul lengkap, tingkat kesulitan dan keabstrakan konsep sesuai dengan tingkat berfikir siswa sehingga dapat diterjemahkan dengan mudah. E-modul juga mendapatkan kategori sangat valid pada aspek evaluasi atau latihan soal. Hal ini 
menunjukkan bahwa evaluasi dalam e-modul sesuai dengan tujuan pembelajaran dan konsep yang berlaku dalam materi IPA. Kunci jawaban dari evaluasi atau latihan soal yang disajikan pada e-modul juga telah benar dan sesuai kaidah yang ada. Petunjuk pengerjaan soal juga disajikan dengan jelas. Selain itu soal yang disajikan juga bervariasi dan tingkat kesulitannya sesuai dengan materi.

E-modul juga memenuhi kriteria pada aspek bahasa dan mendapat kategori sangat valid yang menunjukkan bahwa bahasa yang digunakan mendukung kemudahan dalam memahami alur materi, kalimat yang digunakan dalam e-modul juga efektif dan tata bahasa serta ejaan yang digunakan dalam e-modul tepat sesuai kaidah bahasa. Selain itu, istilah yang digunakan juga tepat dan sesuai serta tidak berubah-ubah. Sebagaimana penelitian yang telah dilakukan oleh Aulia dan Andromeda (2019) e-modul memperoleh kategori kevalidan tinggi pada komponen kebahasan yang menunjukan bahwa bahasa yang digunakan dalam e-modul telah sesuai kaidah bahasa, sehingga dapat memberikan informasi yang mudah dipahami dan tidak menimbulkan kerancuan. Bahan ajar yang baik adalah yang memenuhi komponen kejelasan informasi, kesesuaian kaidah Bahasa Indonesia yang baik dan benar, keterbacaan, serta penggunaan bahasa yang mudah dipahami dan jelas (Depdiknas, 2008). E-modul juga memenuhi aspek efek bagi strategi pembelajaran dan mendapat kategori sangat valid berdasarkan penilaian validator ahli. Hal ini menunjukkan bahwa e-modul mendukung siswa untuk dapat belajar secara mandiri dan meningkatkan pemahaman siswa serta menambah pengetahuan mengenai materi pemanasan global.

Untuk aspek rekayasa perangkat lunak e-modul juga mendapat kategori sangat valid berdasarkan penilaian validator ahli yang menunjukkan bahwa e-modul dapat dioperasikan dengan mudah. Link video dan artikel dalam e-modul juga dapat dengan mudah diakses serta video dan artikel yang disajikan sesuai dengan materi, jelas dan mudah dipahami. Sebagaimana yang telah dikemukakan Kamaruddin (2021) video dan gambar yang disajikan dalam e-modul apabila sesuai dengan konsep materi maka dapat melengkapi pengalamanpengalaman dasar peserta didik dalam menggunakan e-modul baik ketika membaca, berdiskusi dan praktik. Hal ini sejalan dengan pendapat Albo et al. (2015) bahwa video sangat mendukung proses pembelajaran dan mendorong kegiatan pembelajaran menjadi lebih fleksibel, otonom dan signifikan. E-modul juga memenuhi kriteria aspek tampilan visual dan mendapatkan kategori sangat valid berdasarkan penilaian validator ahli. Hal ini menunjukkan bahwa e-modul memiliki desain yang cukup menarik, warna tampilan yang digunakan sesuai, pemilihan warna teks tepat sesuai dengan background, menu, dan materi yang disajikan juga jelas serta gambar yang dipilih tepat dan memiliki proporsi yang baik. Sebagaimana yang dikemukakan oleh Winatha et al. (2018) ukuran, warna, spasi dan gaya teks yang konsisten memberikan kenyamanan siswa dalam menggunakan e-modul, apabila warna teks yang digunakan terang maka latar belakarang atau background harus menggunakan warna gelap, begitu juga sebaliknya. E-modul juga memenuhi kriteria pada aspek pengorganisasian emodul dengan kategori sangat valid berdasarkan penilaian validator ahli. Hal ini menunjukkan bahwa e-modul mudah digunakan, navigasi pada e-modul juga berfungsi dengan baik serta petunjuk e-modul jelas. 


\section{PENUTUP}

E-modul pemanasan global berbasis creative problem solving dikatakan valid karena telah memperoleh persentase skor rata-rata penilaian sebesar 95,71\% dengan kategori sangat valid dari tiga validator ahli terkait aspek relevansi materi, aspek pengorganisasian materi, aspek evaluasi/latihan soal, aspek bahasa, aspek efek bagi strategi pembelajaran, aspek rekayasa perangkat lunak, aspek tampilan visual, dan aspek pengorganisasian e-modul.

Disarankan bagi bagi peneliti lain, hendaknya mengembangkan e-modul pemanasan global berbasis creative problem solving yang lebih menarik dan inovatif lagi serta melakukan uji coba dalam skala yang lebih luas agar dihasilkan e-modul yang lebih baik.

\section{UCAPAN TERIMA KASIH}

Terimakasih kepada Dosen Pembimbing yang telah memberikan arahan dan saran dalam penelitian ini dan juga terimakasih kepada kepala sekolah dan guru pamong yang telah mengizinkan penelitian dan membantu penelitian ini sehingga berjalan dengan lancar.

\section{DAFTAR PUSTAKA}

Akbar, S. 2016. Instrumen Perangkat Pembelajaran. Bandung: PT. Remaja Rosdakarya Offset.

Albo, L., Hernandez-Leo, D., Barcelo, L., dan Sanabria, L. 2015. Video-Based Learning in Higher Education: The Flipped or The Hands-on Classroom? EDEN Annual Conference, Barcelona, Spain.

Arikunto, S. 2008. Dasar-Dasar Evaluasi Pendidikan. Jakarta: Bumi Aksara.

Aulia, A., dan Andromeda, A. 2019. Pengembangan E-Modul Berbasis Inkuiri Terbimbing Terintegrasi Multirepresentasi dan Virtual Laboratory pada Materi Larutan Elektrolit dan Nonelektrolit untuk kelas X SMA/MA. Edukimia, 1(1): 94-102

Depdiknas. 2008. Panduan Pengembangan Bahan Ajar. Jakarta: Direktorat Pembina Sekolah Menengah Atas. Jakarta: Pusat Kurikulum Balitbang Diknas.

Freije, A. M., T. Hussain, dan E. A. Salman. 2017. Global Warming Awareness Among the University of Bahrain Science Students. Journal of the Association of Arab Universities for Basic and Applied Sciences, 9-16.

Kamaruddin, A. N. 2021. Pengembangan Elektronik Modul (E-Modul) Berbasis Socio Scientific Issue (SSI) Terintegrasi Flip PDF Corporate Edition pada Materi Biologi Kelas XI Sekolah Menengah Atas. Universitas Negeri Makasar, 1-11.

Kemendikbud. 2016. Silabus Mata Pelajaran Sekolah Menengah Pertama/Madrasah Tsanawiyah (SMP/MTs). Jakarta: Kementrian Pendidikan dan Kebudayaan.

Pramita, A., dan R. Agustini. 2016. Pengembangan media permaianan ular tangga pada materi senyawa hidrokarbon kelas XI SMA untuk meningkatkan pemahaman konsep. Unesa Journal of Chemical Education, 5(2): 336-344.

Prasetyo, Y. D., R. Yektyastuti, M. Solihah, J. Ikhasn, dan K. H. Sugiyarto. 2015. Pengaruh penggunaan media pembelajaran kimia berbasis aplikasi android terhadap peningkatan motivasi siswa SMA. Prosiding Seminar Nasional Pendidikan Sains V. Universitas Sebelas Maret.

Rochmad, 2012. Model Pengembangan Perangkat Pembelajaran Matematika. Jurnal Kreano, 3(1): 69.

Rustia, E. A., A. Lutfi, dan H. Subekti. 2015. Pengembangan permaianan gaprek kampung sebagai media pembelajaran materi pemanasan global siswa SMP kelas VII. Jurnal Pendidikan Sains e-Pensa, 1(2): 1-7. 
Setianita, O. T., W. Liliawati, dan Muslim. 2019. Identifikasi miskonsepsi siswa SMA pada materi pemanasan global menggunakan four-tier diagnostic test dengan analisis confidence discrimination quotient (CDQ). Prosiding Seminar Nasional FISIKA, 5(1): 186-192.

Sibarani, H. P., M. Komaro, dan Y. Sukrawan. 2019. Implementasi Mobile Learning Berbasis Aplikasi Smartphone Untuk Meningkatkan Hasil Belajar Siswa Pada Mata Pelajaran Teknik Pemesinan Bubut. Journal of Mechanical Engineering Education, 6(1): 42-50.

Swestyani, S., M. Masyuri, dan B. A. Prayitno. 2014. Pengembangan Modul IPA Berbasis Creative Problem Solving untuk Meningkatkan Kemampuan Berpikir Kreatif Siswa. Bio-Pedagogi: Jurnal Pembelajaran Biologi, 6(2): 36-41.

Sudjana. 2005. Metode Statistika. Bandung: Tarsito

Winatha, K. R. 2018. Pengembangan E-Modul Interaktif Berbasis Proyek Mata Pelajaran Simulasi Digital. Jurnal Pendidikan Teknologi dan Kejuruan, 15(2): 188-199.

Yazdanparast, T., S. Salehpour, dan M. R. Masjedi. 2013. Global Warming: Knowledge and Views of Iranian Students. Journal National Research Institute of Tuberculosis and Lung Disease, 51(3): 178-184.

Yusuf. 2005. Evaluasi Pendidikan. Padang: UNP. 